cesano de Cuenca; ahora hay que añadirle este cáliz boliviano. Por su fidelidad a los modelos anteriores de Becerril (especialmente por su nudo en jarrón), podemos asignarle de momento una cronología temprana, en las dos últimas décadas del siglo xvI.

RAFAEL RAMOS SOSA

Universidad de Sevilla

\title{
DE NUEVO SOBRE LA COMPASSIO MARIAE: A PROPÓSITO DE LAS PINTURAS MURALES DE SEPULCRO DE DON ALFONSO VIDAL EN LA CATEDRAL VIEJA DE SALAMANCA
}

En el verano de 1999 quedaron al descubierto tras su restauración las pinturas murales de estilo gótico lineal de los siglos XIII y XIV que se encontraron en noviembre de 1997 en el brazo meridional del crucero de la catedral vieja de Salamanca ${ }^{1}$. Por su cantidad, por su calidad y por la riqueza de su iconografía estos descubrimientos consolidan la importancia de Salamanca en el panorama de la pintura de estilo gótico lineal. No pretendo abordar en este momento un estudio de conjunto acerca de estas pinturas, que reservo para otra ocasión, sino estudiar un aspecto iconográfico relevante de estos descubrimientos que entronca con el objeto de interés de la profesora Domínguez Rodríguez en un artículo publicado no hace mucho tiempo en las páginas de esta revista ${ }^{2}$.

En el brazo meridional del crucero de la catedral vieja de Salamanca existen cuatro sepulcros monumentales con decoración escultórica y pictórica, dos en el muro oriental y dos en el muro meridional (fig. 1). El objeto de mi interés se encuentra en el sepulcro del muro meridional más próximo a la puerta de Acre (la puerta que, abierta en el muro oriental, comunica con el Patio Chico). De este sepulcro eran ya bien conocidas las pinturas del fondo y del intradós de su arcosolio, con representaciones de la Coronación de la Virgen y de diversos santos (fig. 2). En la reciente restauración se ha descubierto la decoración que completaba el conjunto por encima del arcosolio hasta la línea de imposta. El estilo de estas pinturas murales es muy próximo al del Mateos que firma la espléndida Virgen de Misericordia de la parte alta del muro ${ }^{3}$.

La identificación del personaje a quien corresponde este sepulcro y, con ello, de su cronología ha suscitado algunos problemas puestos de nuevo de actualidad con la aparición en la reciente restauración de inscripciones que han aportado nuevas referencias a esta problemática. Los sepulcros de la catedral vieja de Salamanca apenas merecieron una escueta mención de Ponz. Fue en el siglo xix, más sensible a las realizaciones de la Edad Media, cuando se inició su estudio. La primera obra en la que se ofrece una identificación de estos sepulcros es la

\footnotetext{
${ }^{1}$ La noticia de su descubrimiento se difundió en la prensa local a partir del 13 de noviembre de 1997. Algunos días más tarde el canónigo don Daniel Sánchez recordaba que ya en octubre de 1990 había llamado la atención sobre la existencia de pinturas murales que permanecían ocultas. La existencia de pinturas murales en este emplazamiento había sido advertida ya por Gómez-Moreno, que en el catálogo monumental de Salamanca que redactó entre 1901 y 1903 escribió: «hay señal de haberlas tenido el arquito que encabeza la puerta del Acre, otro arco sepulcral del crucero y asimismo...» (GómezMoreno Martínez, Manuel: Catálogo monumental de España. Provincia de Salamanca, Dirección General de Bellas Artes, Valencia, 1967, p. 133). La obra de Gómez-Moreno permaneció inédita hasta 1967, pero Tormo se sirvió de ella en un estudio publicado ca. 1930 en el que escribió: «Por encima del portón a la calle que se llamó «Puerta de Acre»: se ven restos de pinturas murales» (Tormo y Monzó, Elías: Salamanca: las catedrales (sobre estudios inéditos de don Manuel Gómez-Moreno), Patronato Nacional del Turismo, Madrid, s. a., p. 54).

${ }^{2}$ Domínguez Rodríguez, Ana: «"Compassio" y "Co-redemptio" en las cantigas de Santa María. Crucifixión y Juicio Final», Archivo Español de Arte, tomo LXXI, Madrid, 1998, pp. 17-35.

${ }^{3}$ Gutiérrez Baños, Fernando: «Pintura de estilo gótico lineal en Castilla y León», en XIII Congreso Nacional de Historia del Arte: Ante el nuevo milenio: raíces culturales, proyección y actualidad del arte español (Granada, 2000), Universidad de Granada, Granada, 2000, volumen II, p. 1106, foto 6.
}

AEA, LXXV, 2002, 297, pp. 51 a 88 

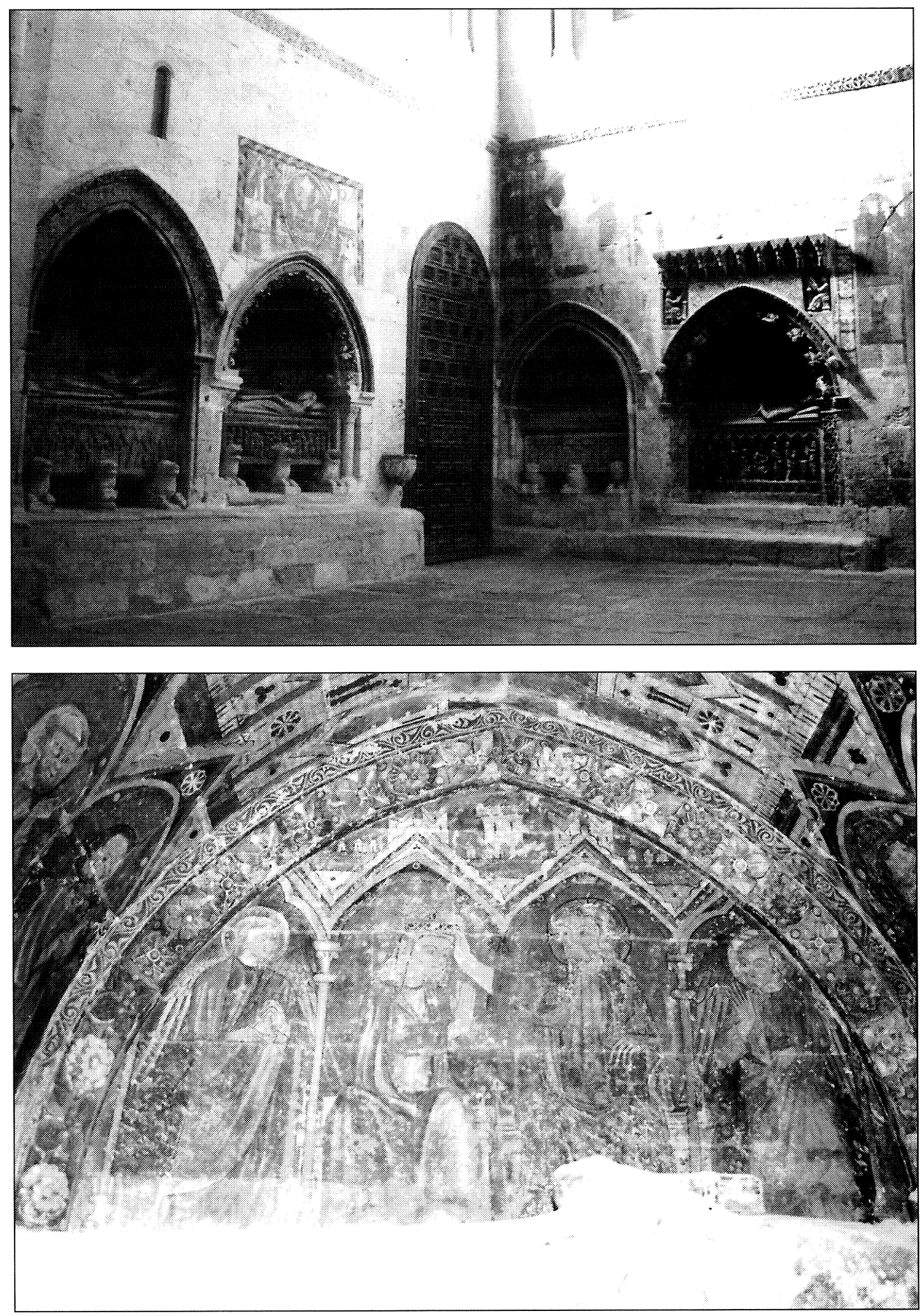

Fig. 1. Salamanca, catedral vieja; brazo meridional del crucero.

Fig. 2. Salamanca, catedral vieja; sepulcro de don Alfonso Vidal (†1288 ó 1289): Coronación de la Virgen.

AEA, LXXV, 2002, 297, pp. 51 a 88 
edición revisada (tan revisada que, de hecho, es una obra independiente) del Compendio histórico de la ciudad de Salamanca de Bernardo Dorado publicada en 1861 (de nuevo en 1863) por Manuel Barco y, por Ramón Girón ${ }^{4}$. En ella, tras insistir una y otra vez en que estos enterramientos carecen de epitafios ${ }^{5}$, el sepulcro que aquí nos interesa se adscribe a don Alfonso Vidal, «deán de Ávila y canónigo de Salamanca», y se considera que es obra de finales del siglo XIII o de comienzos del siglo xIv. El trabajo de Barco y de Girón fue objeto de severas críticas tanto por parte de Quadrado como por parte de Araújo ${ }^{6}$, pero esto no impidió que sus propuestas (que, aunque no se declara, se basan en la consulta del libro de aniversarios de la catedral) fuesen asumidas retrotrayéndolas a la autoridad de Dorado (así Quadrado o GómezMoreno). Quadrado mostró sus reservas con respecto a la identificación del sepulcro más próximo a la puerta del claustro con el del chantre don Aparicio, pero admitió que el sepulcro que aquí nos interesa pertenecía a don Alfonso Vidal ${ }^{7}$. Villar y Macías enriqueció el panorama al recoger informaciones más precisas tomadas del libro de aniversarios y de otros documentos del archivo de la catedral, pero su interés por la consulta de los documentos le llevó a introducir algunos errores al no considerar la frecuencia con que se repiten los nombres a lo largo de los siglos xiII y xIV (así, por ejemplo, da el apellido Guillén al chantre don Aparicio - sobre cuya sepultura propone una explicación alternativa a la de Quadrado que le permite seguir adscribiéndole el sepulcro más próximo a la puerta del claustro- cuando, en realidad, ese apellido corresponde a otro personaje). En cualquier caso, Villar y Macías mantiene la adscripción a don Alfonso Vidal del sepulcro que aquí nos interesa ${ }^{8}$.

A comienzos del siglo xx resulta decisiva la aportación de Gómez-Moreno en la redacción del catálogo monumental de la provincia de Salamanca. Gómez-Moreno consultó la documentación del archivo de la catedral y aportó nuevos datos sobre don Alfonso Vidal, del que dio a conocer que vivía de 1282 a 1287 y que era, además, arcediano de Alba. Sin embargo, a partir de las referencias del libro de aniversarios que sitúan su enterramiento «como entran por la puerta de Acre a mano izquierda, en un arco afigurado», a partir de la evidente relación estilística existente entre el sepulcro más próximo a la puerta del claustro (el que desde «Dorado» (sic) había venido siendo atribuido, en ocasiones con reservas, al chantre don Aparicio o don Aparicio Guillén) y un sepulcro de la catedral de Ávila, de cuyo cabildo era deán don Alfonso Vidal, y a partir, finalmente, de la presencia en este sepulcro, en el relieve del fondo de su ar-

\footnotetext{
${ }^{4}$ Barco López, Manuel y Girón, Ramón: Historia de la ciudad de Salamanca que escribió don Bernardo Dorado corregida en algunos puntos, aumentada y continuada hasta nuestros días por varios escritores naturales de esta ciudad, Juan Sotillo, Salamanca, 1861, p. 76.

${ }^{5}$ En realidad tanto el sepulcro de don Diego López, arcediano de Ledesma, como el sepulcro de don Aparicio, chantre de Salamanca, tienen epitafios que eran visibles en 1861, si bien es más que probable que la ubicación del de este último esté modificada en el siglo XVIII.

${ }^{6}$ Quadrado escribió: «Sensible es que los errores en que abunda la historia de Dorado tal como se publicó en 1861, adicionada o más bien rehecha por modernos escritores, nos inspiren casi la misma desconfianza que la de Gil González Dávila, mientras sus indicaciones no vayan apoyadas en testimonios fehacientes» (Quadrado, José María: Salamanca, Ávila y Segovia (Recuerdos y bellezas de España, volumen XII), Francisco Javier Parcerisa, Barcelona, 1865, p. 22 (nota)). Araújo, por su parte, afirmó: «Girón y Barco, al refundir y adicionar la Historia de Salamanca de Dorado, no hicieron otra cosa que aumentar su confusión y falta de método, barajándolo todo sin crítica alguna y produciendo un libro voluminoso de indigesta y desapacible lectura» (Araújo Gómez, Fernando: La reina del Tormes, Jacinto Hidalgo, Editor, Salamanca, 1884 , tomo I, p. ix).

${ }^{7}$ Quadrado, José María: o. cit., pp. 35-36. Siguen a Quadrado Falcón y Araújo (Falcón Ozcoiti, Modesto: Salamanca artística y monumental o descripción de sus principales monumentos, Telesforo Oliva, Salamanca, 1867, pp. 82-83; Araújo Gómez, Fernando: o. cit., tomo II, pp. 21-22).

${ }^{8}$ Villar y Macías, Manuel: Historia de Salamanca, s. e., Salamanca, 1887, tomo I, pp. 135-138. Villar y Macías es el primero que menciona la Coronación de la Virgen de este sepulcro, pero no dice que sea una pintura. A la altura de 1887 las pinturas murales de los sepulcros del brazo meridional del crucero de la catedral vieja de Salamanca habían sido puestas en valor con la publicación de dos espléndidas láminas en la colección Monumentos arquitectónicos de España. Sigue a Villar y Macías Vicente Bajo (Vicente Bajo, Juan Antonio: Guía descriptiva de los principales monumentos arquitectónicos de Salamanca, Imprenta de Calatrava, Salamanca, 1901, pp. 27-30).
}

$A E A, \mathrm{LXXV}, 2002,297$, pp. 51 a 88 
cosolio (en el que se desarrolla una Crucifixión) de las figuras orantes de un clérigo y de una mujer, que conviene con la fundación por parte de don Alfonso Vidal de un aniversario por el alma de su hermana doña Teresa, Gómez-Moreno atribuyó a don Alfonso Vidal el sepulcro más próximo a la puerta del claustro y consideró anónimo el sepulcro más próximo a la puerta de Acre que hasta ahora se le atribuía, ya que el chantre don Aparicio (al que cuidadosamente no aplica el apellido «Guillén») «yace en otro arco liso inmediato, donde está su epitafio» ${ }^{9}$. La cuidada argumentación de Gómez-Moreno no fue publicada hasta 1967 y con anterioridad sus aportaciones sólo fueron conocidas de manera indirecta o parcial, lo que contribuyó a alimentar algunos errores en torno a la ya compleja cuestión de la identificación de los sepulcros del brazo meridional del crucero de la catedral vieja de Salamanca.

A lo largo del primer tercio del siglo xx se publicaron algunos trabajos (singularmente el de Post) que, al margen de las aportaciones de Gómez-Moreno, mantuvieron la identificación tradicional y adscribieron, por lo tanto, el sepulcro que aquí nos interesa a don Alfonso Vidal ${ }^{10}$. En torno a 1930 se publicó un libro de Tormo en el que por vez primera se difundían, si bien de forma escueta y, en ocasiones, confusa, las aportaciones de Gómez-Moreno. A partir de aquí han ido surgiendo algunos errores que en absoluto se encuentran en la obra de Gómez-Moreno. El primer error es considerar que el chantre don Aparicio Guillén (sic) murió en 1287 y que le corresponde el sepulcro más próximo a la puerta del claustro. En realidad ni el chantre se apellidaba Guillén ni murió en 1287, sino en 1274, como consta en su epitafio (publicado en varias ocasiones desde el siglo XIX). Sin duda este error se debe a la difusión por parte de Tormo de que don Alfonso Vidal vivía entre 1282 y 1287 (lo cual no significa, en absoluto, que muriese en este último año) y de que es posible que a este personaje corresponda el sepulcro que, según él, conviene seguir llamando del chantre don Aparicio (!) ${ }^{11}$. El error, matizado en ocasiones por expresiones como «supuesto», aparece por vez primera en una obra de Camón Aznar de 1932 y va asociado al mantenimiento de las identificaciones tradicionales de los enterramientos, al margen del contenido real de la propuesta de Gómez-Moreno ${ }^{12}$. Con la publicación, finalmente, en 1967 del catálogo monumental de Gómez-Moreno la crítica más especializada se ha hecho eco de sus aportaciones y ha atribuido a don Alfonso Vidal el sepulcro más próximo a la puerta del claustro ${ }^{13}$, pero al hilo de esta revisión de la adscripción de los enterramientos se ha deslizado un

\footnotetext{
${ }^{9}$ Gómez-Moreno Martínez, Manuel: o. cit., pp. 118-119 y 131.

${ }^{10}$ Tormo y Monzó, Elías: «Pintura», en Enciclopedia universal ilustrada europeo-americana, tomo XXI (España), Espasa-Calpe, Madrid, 1923, p. 1267; Post, Chandler Rathfon: A History of Spanish Painting, Harvard University Press, Cambridge (Massachusetts), 1930, volumen II, pp. 147-148.

11 Tormo y Monzó, Elías: Salamanca: las catedrales (sobre estudios inéditos de don Manuel Gómez-Moreno), Patronato Nacional del Turismo, Madrid, s. a., pp. 54-55.

${ }^{12}$ Camón Aznar, José: Guía de Salamanca, Patronato Nacional de Turismo, Madrid, 1932, pp. 44-45; García Boiza, Antonio: Salamanca monumental, Editorial Plus-Ultra, Madrid, s. a., pp. 64-65 (este autor no menciona el sepulcro de don Alfonso Vidal); Camón Aznar, José: Salamanca (guía artística), Junta Provincial de Turismo, Salamanca, 1953, pp. 58-59; Cirlot, Juan Eduardo: Salamanca y su provincia, Editorial Aries, Barcelona, 1956, pp. 45-46; Durán Sanpere, Agustín y Ainaud de Lasarte, Juan: Escultura gótica (Ars Hispaniae, volumen VIII), Madrid, 1956, pp. 89-90 (estos autores omiten el apellido Guillén al mencionar al chantre don Aparicio). Este planteamiento sigue vigente, aun después de la publicación del catálogo de Gómez-Moreno, en Sánchez y Sánchez, Daniel: La catedral vieja de Salamanca, Daniel Sánchez y Sánchez, Salamanca, 1991, pp. 101-103. No se refieren al sepulcro del chantre don Aparicio Guillén, pero mantienen la adscripción tradicional del sepulcro más próximo a la puerta de Acre a don Alfonso Vidal: Cook, Walter William Spencer y Gudiol Ricart, José: Pintura e imaginería románicas (Ars Hispaniae, volumen VI), Editorial Plus-Ultra, Madrid, 1950, p. 183 ( $2^{a}$ ed., Editorial Plus-Ultra, Madrid, 1980, p. 244); Camón Aznar, José: Pintura medieval española (Summa Artis, volumen XXII), Espasa-Calpe, Madrid, 1966, p. 155; VV.AA.: La pintura española (La pintura en Europa), Electa, Milán, 1995, tomo I, p. 74 (el capítulo sobre pintura gótica se debe a Joaquín Yarza Luaces).

${ }^{13}$ Rodríguez Gutiérrez de Ceballos, Alfonso: Las catedrales de Salamanca, Editorial Everest, León, 1978, p. 25; Martínez Frías, José María: «Los monumentos religiosos (edad media)», en Cabo Alonso, Ángel y Ortega Carmona, Alfonso (coors.): Salamanca. Geografía. Historia. Arte. Cultura, Ayuntamiento de Salamanca, Salamanca, 1986, p. 336; Azcárate Ristori, José María de: Arte gótico en España, Ediciones Cátedra, Madrid, 1990, p. 186; Sureda i Pons, Joan: La pintura protogótica (Cuadernos de Arte Español, número 27), Historia 16, Madrid, 1992, p. 12; Casaseca Casaseca, Antonio: Las
}

$A E A, \mathrm{LXXV}, 2002,297$, pp. 51 a 88 
segundo error que es el de atribuir al inexistente chantre don Aparicio Guillén, fallecido en 1287, el sepulcro más próximo a la puerta de Acre en lugar de mantener para este sepulcro la anonimia propugnada por Gómez-Moreno ${ }^{14}$. El fundamento de este error se encuentra en que, de hecho, en la lámina 54 del catálogo monumental el pie de lámina atribuye este sepulcro (aunque con una interrogación) al chantre don Aparicio, en contra de lo argumentado en el texto.

En el momento presente son, por lo tanto, tres las hipótesis en torno a la identificación del sepulcro que nos ocupa, a saber: 1) el sepulcro corresponde a don Alfonso Vidal (hipótesis tradicional que arranca de los editores de Dorado); 2) el sepulcro es anónimo, puesto que a don Alfonso Vidal corresponde el sepulcro más próximo a la puerta del claustro (hipótesis de Gómez-Moreno); 3) el sepulcro corresponde al chantre don Aparicio Guillén, fallecido en 1287 (hipótesis que se basa en interpretaciones erróneas de Gómez-Moreno). La tercera hipótesis debe rechazarse por su espúrea fundamentación y para dirimir la cuestión de la adscripción del sepulcro resulta imprescindible, de entrada, la revisión de la documentación.

La fuente más importante en este sentido es el ya mencionado libro de aniversarios ${ }^{15}$. Este documento, que a veces incurre en alguna que otra contradicción, fue elaborado a comienzos del siglo xvi. Con el sepulcro que aquí nos interesa se relacionan dos entradas del libro de aniversarios. La primera, correspondiente al 17 de agosto, comienza: Por don Alonso Vidal, deán de Áuila, canónigo de Salamanca, que yaze commo entran por la puerta de Acre a la mano isquierda... (f. xviii-v). La segunda, correspondiente al 4 de febrero, comienza: Por el deán de Ávila, canónigo de Salamanca, que yaze a la puerta de Acre en vn arco afigurado... (f. lxv-v). La expresión arco afigurado es la utilizada en el libro de aniversarios para describir monumentos funerarios del tipo del que nos ocupa y, aunque no aparezca en la entrada del 17 de agosto, es evidente que esta entrada corresponde al mismo personaje al que se refiere la entrada del 4 de febrero, en la que no se consigna su nombre, por la identidad de las dignidades (deán de Ávila y canónigo de Salamanca en ambos casos), por la identidad de las rentas vinculadas a los dos aniversarios (rentas del lugar de La Orbada en ambos casos) y, finalmente, por la correspondencia de las fechas de celebración de los aniversarios con las instituidas por don Alfonso Vidal en el documento fundacional de 7 de diciembre de 1286 (terçer dia despues de la festa de Santa Maria de Agosto y terçer dia despues de la festa de Santa Maria de Febrero ${ }^{16}$. La documentación nos pone ante la evidencia de que don Alfonso Vidal está enterrado en un sepulcro monumental que se encuentra a mano izquierda según se entra en la catedral por la puerta de Acre. Ahora bien, en este emplazamiento existen dos sepulcros monumentales, uno más próximo a la puerta de Acre y otro más próximo a la puerta del claustro. En principio hay que entender que con las expresiones a la puerta de Acre y commo entran por la puerta de Acre a la mano isquierda los redactores del libro de aniversarios se refieren al sepulcro más próximo a esta puerta: si hubiesen querido aludir al otro sepulcro hubiesen empleado como referencia la puerta del claustro ${ }^{17}$. El problema está en que para el sepulcro más

catedrales de Salamanca, Edilesa, León, 1993, pp. 36-37 (este autor es el que de manera más cuidada recoge las argumentaciones de Gómez-Moreno).

${ }^{14}$ Rodríguez Gutiérrez de Ceballos, Alfonso: 1. cit.; Azcárate Ristori, José María de: 1. cit.. (p. 283, en cambio, se refiere a este sepulcro como anónimo); Sureda i Pons, Joan: 1. cit.; Casaseca Casaseca, Antonio: o. cit., p. 37 (en el pie de foto, pues en el texto, como se ha indicado, recoge de manera cuidada las argumentaciones de Gómez-Moreno).

${ }^{15}$ Archivo de la Catedral de Salamanca, caj. 67.

${ }^{16}$ La documentación catedralicia de los siglos XII y XIII está publicada en su integridad, por lo que cito los documentos de este período según la edición: Martín Martín, José Luis, Villar García, Luis Miguel, Marcos Rodríguez, Florencio y Sánchez Rodríguez, Marciano: Documentos de los archivos catedralicio y diocesano de Salamanca (siglos XII-XIII), Universidad de Salamanca, Salamanca, 1977 (en lo sucesivo Documentos...), doc. núm. 406 (pp. 511-512).

${ }^{17}$ Así ocurre en el caso de los sepulcros del muro oriental del brazo meridional del crucero, en el que la puerta de Acre se utiliza como referencia para ubicar el sepulcro más próximo a ella (el de doña Elena), mientras que para ubicar el otro sepulcro (el de don Diego López, arcediano de Ledesma) se utiliza como referencia el arca de la obra, que algunas referencias más precisas sitúan cabe la capilla de sant Niculás (ff. lxx-r, 1xxv-v y lxxviii-r).

AEA, LXXV, 2002, 297, pp. 51 a 88 


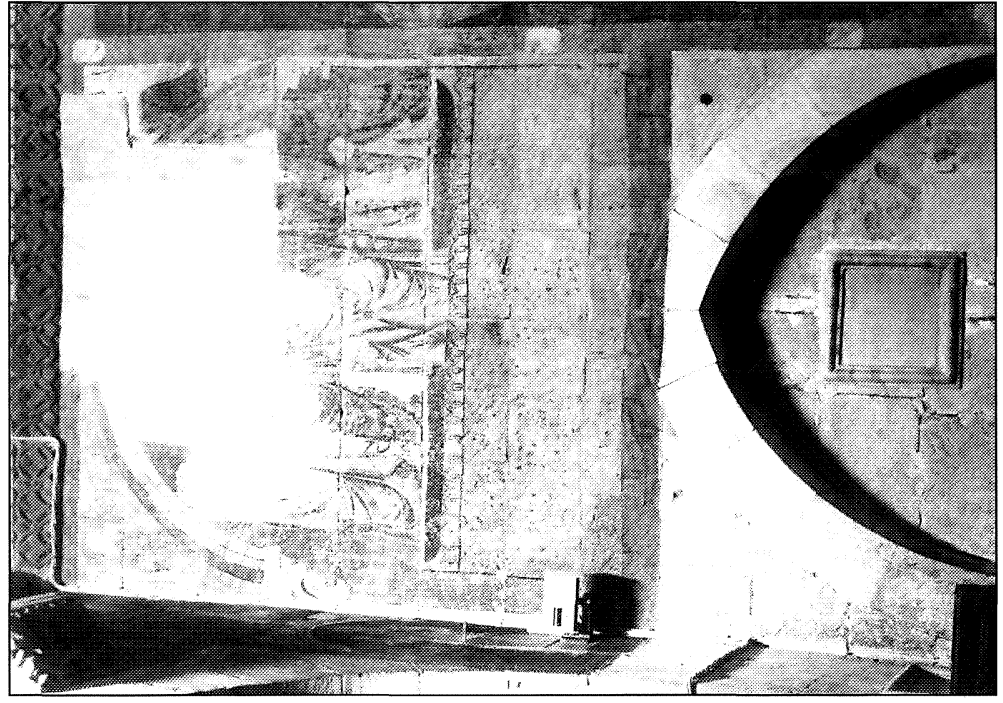

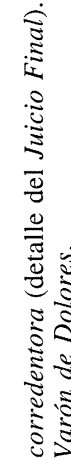

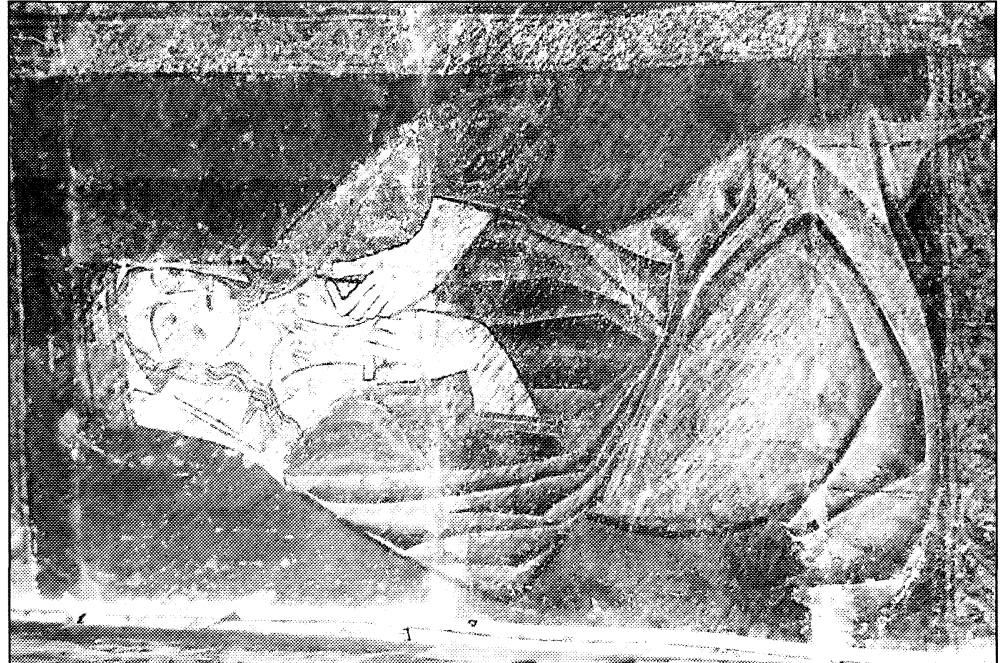

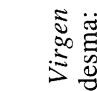

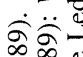

웜

10.0 \&

$\infty$

士t

要

요

选

흠 훙

용

을

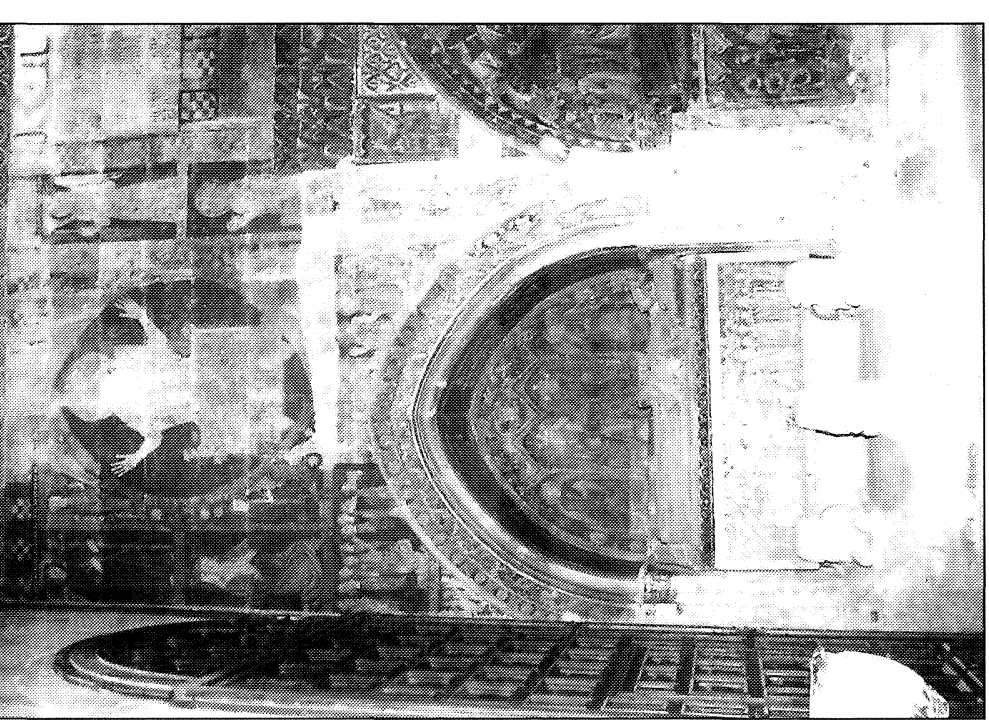

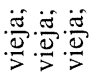

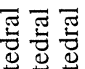

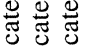

ฮే ฮீ శீ

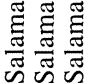

$\dot{\theta} \dot{\theta} \dot{1}$

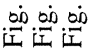

$A E A, \mathrm{LXXV}, 2002,297$, pp. 51 a 88 
próximo a la puerta del claustro no se detecta en el libro de aniversarios referencia alguna ${ }^{18}$, por lo que, ante este vacío, Gómez-Moreno, consciente de las contradicciones en que en ocasiones incurre esta valiosa fuente, prefirió dejarse llevar por las evidencias estilísticas e iconográficas reseñadas. La apuesta de don Manuel era coherente, aunque arriesgada, pero los últimos descubrimientos han venido a desmentirla. Sobre el sepulcro más próximo a la puerta del claustro ha aparecido una bella inscripción pintada (bella tanto por lo cuidado de sus letras góticas mayúsculas como por el latín en que está redactada, más allá de lo que son los escuetos epitafios al uso) que considero vinculada sin duda a este sepulcro y en la que por dos veces se lee un nombre que no es el de don Alfonso Vidal: don Alfonso Vidal es, sin duda, el personaje a quien corresponde el sepulcro que aquí nos interesa.

Establecida con precisión la identificación del sepulcro de don Alfonso Vidal conviene indagar en la biografía de este personaje para delimitar la cronología de su sepulcro. Los estudios de Martín Martín sobre la iglesia de Salamanca ${ }^{19}$ y la cuidada edición de los documentos catedralicios de los siglos XII y XIII ${ }^{20}$ hacen que sea más fácil hoy reconstruir su biografía y enriquecer la información aportada por los editores de Dorado y por Gómez-Moreno. Don Alfonso Vidal fue un eclesiástico de prominente posición perteneciente a una familia con una sólida presencia en el cabildo de Salamanca ${ }^{21}$. Su relevancia se pone de manifiesto en el hecho de que acumulase varias prebendas (algo combatido en vano por las autoridades) y en el de que éstas fuesen, además, las más apetecibles: un decanato (el de la iglesia de Ávila) y un arcedianato (el de Alba y de Salvatierra en la iglesia de Salamanca). Decanato y arcedianato representan, respectivamente, el honor y el dinero, según Martín Martín ${ }^{22}$. Don Alfonso Vidal aparece por vez primera en la documentación como canónigo de Salamanca en 1266. En 1275 aparece como deán de Ávila. Como arcediano de Alba y de Salvatierra aparece sólo a partir de 1286, pero es probable que ostentase esta dignidad anteriormente (en efecto, no es infrecuente que a un personaje se le mencione sólo por la más elevada de las dignidades que ostenta). En 1282 don Alfonso Vidal se encontraba en Italia. De ese año son cinco documentos datados en Orvieto entre el 27 de febrero y el 29 de abril que constituyen una serie singular en la documentación catedralicia por ser los únicos documentos italianos de origen no pontificio. Se trata de documentos de carácter privado en los que don Alfonso Vidal se encuentra en un aprieto por las deudas contraídas con algunos mercaderes italianos. Por estos documentos no es posible saber demasiado acerca de las razones del viaje de don Alfonso Vidal a Italia, pero Martín Martín sospecha que se trató de alguna misión de carácter institucional ${ }^{23}$. De nuevo en España, en 1286-1287, sintiendo cercano el momento de su muerte, don Alfonso Vidal realizó algunas donaciones al cabildo de Salamanca con cargas de aniversarios por él y por su hermana doña Teresa ${ }^{24}$. En 1289 ya ha fallecido,

\footnotetext{
${ }^{18}$ No cabe identificarlo, desde luego, con el sepulcro del chantre don Aparicio $(\dagger 1274)$, que el libro de aniversarios ubica con absoluta precisión en vn arco qu'está entre las puertas de la sacristía y de la claustra (f. lxvi-r), emplazamiento apuntado, si bien tal vez no con la deseable claridad, por Gómez-Moreno (Gómez-Moreno Martínez, Manuel: o. cit., p. 118). Considero que este sepulcro está modificado en el siglo XVIII.

${ }^{19}$ Especialmente Martín Martín, José Luis: El cabildo de la catedral de Salamanca (siglos XII-XIII), Centro de Estudios Salmantinos, Salamanca, 1975

${ }^{20}$ v. supra n. 16.

${ }^{21}$ Afirmo esto por la documentación, no por la heráldica que aparece en su sepulcro, que se repite también en el de don Diego López, arcediano de Ledesma, en el sepulcro más próximo a la puerta del claustro, en la pintura de San Cristóbal que ha aparecido junto a la puerta de la sacristía y en la Virgen de Misericordia que ha aparecido en la parte alta del muro meridional. Considero que esta heráldica es de carácter corporativo.

${ }^{22}$ Martín Martín, José Luis: o. cit., pp. 35-36.

${ }^{23}$ Martín Martín, José Luis: o. cit., p. 38.

${ }^{24}$ Documentos que se refieren a don Alfonso Vidal: Documentos..., docs. núms. 312 (pp. 403-404), 348 (pp. 445-446), 383, 384, 385, 387, 388 (pp. 480-487), 406, 407 (pp. 511-513), y 437 (pp. 549-550). En la documentación abulense también se encuentra alguna referencia a don Alfonso Vidal: Barrios García, Ángel: Documentación medieval de la catedral de Ávila, Ediciones Universidad de Salamanca, Salamanca, 1981, doc. núm. 146 (pp. 130-144).
}

$A E A$, LXXV, 2002, 297, pp. 51 a 88 
pues en este año figura como arcediano de Alba y de Salvatierra don Diego Fernández ${ }^{25}$. Teniendo en cuenta que este don Diego Fernández, cuya carrera en el cabildo de Salamanca fue deslumbrante, no era más que chantre en $1288^{26}$ (es decir, que en 1288 aún no había podido acceder al arcedianato de Alba y de Salvatierra, sin duda porque aún vivía don Alfonso Vidal), entiendo que la muerte de don Alfonso Vidal se produjo en 1288 ó 1289.

El sepulcro de don Alfonso Vidal se realizaría de inmediato y gracias a la reciente restauración, en la que se ha recuperado en la medida de lo posible la decoración pictórica que se extiende sobre el arcosolio hasta la línea de imposta, podemos contemplarlo hoy con la apariencia que tendría ca. 1290 (fig. 3). En esta parte se desarrolla una interesante representación del Juicio final. La elección de este tema recoge una tradición apenas iniciada algunos años antes en la catedral de Salamanca en el sepulcro de doña Elena $(\dagger 1272)$ en el muro oriental del brazo meridional del crucero ${ }^{27}$ y en el sepulcro de don Fernando Alfonso († 1285), deán de Santiago de Compostela y arcediano de Salamanca, en el muro del lado de la Epístola de la capilla mayor. El sepulcro de don Alfonso Vidal es el que de una manera más completa desarrolla este tema y le asegura una vigencia que se manifiesta en un sepulcro anónimo de la panda meridional del claustro ${ }^{28}$ y en el sepulcro del obispo fray Pedro ( $\dagger 1324$ ) en la capilla de San Nicolás ${ }^{29}$ y que culmina de manera espectacular en las pinturas murales de Nicolás Florentino en la capilla mayor que, en parte, puede ser entendida como la capilla funeraria del obispo don Sancho de Castilla ( $\dagger$ 1446) ${ }^{30}$. En todas estas representaciones se toma como referencia la visión de San Mateo, con Cristo mostrando las llagas como figura central, pero en las más antiguas de ellas (en la del sepulcro de don Alfonso Vidal y en las de los que le preceden, así como en la del sepulcro anónimo del claustro) se produce una extraña pervivencia de la iconografía anterior que lleva a presentar a Cristo dentro de una mandorla rodeado por los cuatro vivientes (en el sepulcro de don Alfonso Vidal se les representa también en forma humana) de acuerdo con la visión apocalíptica. En el sepulcro de don Alfonso Vidal se representa en la parte inferior, en la zona correspondiente a las enjutas del arcosolio, a los resucitados que acuden al juicio y a los justos (con coronas o con nimbos) que ya han alcanzado la salvación. Se evita la referencia a los réprobos. En la parte superior, a ambos lados de Cristo y de los evangelistas, se disponen ángeles con los símbolos de la pasión y los intercesores: San Juan Evangelista (a la derecha, prácticamente perdido) y la Virgen. Es, precisamente, la Virgen la figura más sorprendente de toda la composición (fig. 4). En lugar de adoptar la característica actitud orante María se abre enérgicamente las vestiduras para mostrar su pecho y, lo que es aún más excepcional (y, en la medida de mis conocimientos, único), muestra sobre él una serie de llagas de manera análoga a como lo hace Cristo.

La presencia misma de la Virgen en el Juicio final, que no se basa en fuentes evangélicas, se justifica por el privilegiado papel que como mediadora ante Cristo se le atribuye ya desde los primeros siglos del cristianismo, aunque fue San Bernardo de Claraval quien más decidi-

\footnotetext{
${ }^{25}$ Documentos..., doc. núm. 416 (pp. 524-525).

${ }^{26}$ Documentos..., doc. núm. 410 (pp. 515-516).

${ }^{27}$ La composición con el Juicio final, que se extiende, como en el sepulcro de don Alfonso Vidal, por encima del arcosolio, ha sido descubierta, asimismo, en la reciente restauración. Últimamente se ocupa de este sepulcro Ruiz Maldonado, Margarita: «La dama, el caballero y el eclesiástico en tres sepulcros salmantinos», en Melero Moneo, María Luisa et alii (eds.): Imágenes y promotores en el arte medieval. Miscelánea en homenaje a Joaquín Yarza Luaces, Universitat Autònoma de Barcelona, Bellaterra (Barcelona), 2001, pp. 599-603, que no cree que las pinturas murales de la parte superior correspondan al mismo.

${ }^{28}$ Se trata de un sepulcro que conserva unas pinturas murales muy deterioradas que no han merecido más que una circunstancial referencia de Post (Post, Chandler Rathfon: o. cit., volumen II, p. 147).

${ }^{29}$ También se podría considerar dentro de esta relación otra representación pictórica del Juicio final en un contexto funerario (aunque no se relacione de manera precisa con un enterramiento), a saber, la que se encuentra en el muro septentrional de la capilla de San Martín.

${ }^{30}$ Panera Cuevas, Francisco Javier: El retablo de la catedral vieja y la pintura gótica internacional en Salamanca, Centro de Estudios Salmantinos, Salamanca, 1995, pp. 65-69.
} 
damente contribuyó al éxito de esta idea en Occidente en el siglo XII ${ }^{31}$. El protagonismo de María en el final de los tiempos se vio reforzado por las reflexiones que desde en torno a 1100 se sucedieron acerca del sufrimiento de María durante la pasión: María habría sufrido una compassio paralela a la passio de Cristo y, en virtud de ella, se elevaría hasta la posición de coredemptrix. Domínguez Rodríguez nos ha recordado los testimonios literarios que jalonan el desarrollo de esta idea ${ }^{32}$ y el protagonismo de Ernaldo de Chartres ( $\dagger 1156$ ), que en su De laudibus Beatae Mariae Virginis afirma que el sacrificio del Calvario fue un único sacrificio ofrecido al Padre conjuntamente por Cristo y por María y que ésta recibió en su espíritu las heridas que Cristo recibió en su carne. Ernaldo de Chartres describe además a María mostrando a su Hijo los pechos que le amamantaron para interceder por los hombres y para que éste, mostrando sus llagas al Padre, se apiade de ellos en una auténtica scala salutis. En el siglo XIII San Alberto Magno ( $† 1280)$ insiste en la idea del sufrimiento de María en el Calvario y señala que respondería al cumplimiento de la profecía de Simeón.

La dramática representación de la Virgen pintada ca. 1290 en el sepulcro de don Alfonso Vidal nos ofrece una plasmación concreta de las llagas espirituales que le atribuyen Ernaldo de Chartres y San Alberto Magno, que son el correlato preciso de las de su Hijo y que subrayan su carácter de corredentora. Esta plasmación de las llagas de María carece de paralelo iconográfico conocido y, en cualquier caso, esta representación de la Virgen como corredentora es de una gran antigüedad, sólo superada por los ejemplos del «códice rico» de las Cantigas de Santa María (San Lorenzo de El Escorial, Real Biblioteca, ms. T.I.1) estudiados por Domínguez Rodríguez ${ }^{33}$. Las raíces de la representación deben de ser distintas en cada caso, pues en el manuscrito alfonsí se da una representación de los senos que no aparece en el sepulcro de don Alfonso Vidal y no se da, en cambio, la representación de las llagas. Estas diferencias plantean si existirían modelos iconográficos o si estamos ante creaciones surgidas de fuentes literarias.

Es preciso subrayar, finalmente, que este tipo de iconografía que hace hincapié en el patetismo y en la exhortación a los sentimientos aparece de manera muy temprana en la catedral de Salamanca (quién sabe si el punto de partida se encontraría en la arruinada Crucifixión de las pinturas murales de Antón Sánchez de Segovia en la capilla de San Martín, de 1262), no sólo por la presencia de esta espléndida corredentora en el sepulcro de don Alfonso Vidal, sino también por la del tema del Varón de Dolores en el sepulcro del obispo don Rodrigo Díaz ( $\dagger$ 1339) en la capilla de San Martín y en la recién descubierta pintura funeraria de don Diego, arcediano de Ledesma, en el brazo meridional del crucero, en torno a la puerta del claustro, de cronología incluso anterior (fig. 5) ${ }^{34}$.

FERNANDo GutiÉRREZ BaÑos

Universidad de Valladolid

\footnotetext{
${ }^{31}$ Réau, Louis: Iconografía de la Biblia. Nuevo Testamento (Iconografía del arte cristiano, tomo 1, volumen 2,), Ediciones del Serbal, Barcelona, 1996, pp. 119-120.

${ }^{32}$ Domínguez Rodríguez, Ana: o. cit., pp. 23 y 29-30.

${ }^{33}$ Domínguez Rodríguez, Ana: o. cit., pp. 26 y ss.

${ }^{34}$ Empleo la expresión Varón de Dolores en el sentido genérico en el que la utiliza Réau (Réau, Louis: o. cit., p. 46). En ambos casos se trata de representaciones en las que aparece Cristo de pie, dentro del sepulcro, rodeado por otros personajes.
}

AEA, LXXV, 2002, 297, pp. 51 a 88 